\title{
Neonatal intensive care cots: estimating the population based requirement in Trent, UK
}

\author{
Paul R Burton, Elizabeth Draper, Alan Fenton, David Field
}

\begin{abstract}
Study objectives - To estimate the population based requirement for neonatal intensive care (NIC) cots by investigating NIC utilisation in a large population based study.

Design and setting - This was a two year, non-randomised, prospective cohort study of neonates receiving NIC in hospitals in the Trent Regional Health Authority (RHA).
\end{abstract}

Participants - The main study considered the 2979 neonates born to Trent RHA residents who had begun high dependency care in Trent RHA or neighbouring health authorities between 1 April 1990 and 31 March 1992 and met any of the following criteria: (i) birth weight $<1500$ g; (ii) gestation <32 weeks; (iii) need for active respiratory support other than initial resuscitation; (iv) need for in utero or neonatal transfer to receive high dependency care; (v) severe asphyxial brain insult after delivery; and (vi) death. The analysis here is restricted to the 1730 neonates who received total parenteral nutrition or assisted ventilation, or both; that is, those who received NIC level 1 (ICL1) on at least one day.

Measurements and analysis - The treatment history of each neonate was converted into a time-line detailing the dates of beginning and stopping NIC, the dates of any transfers between units, and any gaps in NIC treatment. The duration of ICL1 was observed directly and that of intensive care level 2 (ICL2) was imputed from a model based upon round trip transfers. These were also recorded on the timeline. The time-lines were first used to derive the observed distribution of the utilisation of NIC cots in Trent RHA during the study. An extensive series of Monte Carlo simulations was then carried out in order; (i) to estimate cot requirements in smaller populations; (ii) to determine whether Trent RHA utilised its NIC cots in a manner that was clinically appropriate at the population based level; (iii) to perform a series of sensitivity analyses; and (iv) to compare results with an equivalent study carried out in the Northern RHA.

Main results and conclusions - Trent RHA is reasonably representative of the greater population of England and Wales in terms both of the distribution of birth weight and of birth weight-specific neonatal mortality. Trent RHA did not seem to be underprovided for NIC cots or to be overusing these cots inappropriately. It therefore seems reasonable, if the assumptions of the analysis are borne carefully in mind, to treat these utilisation data as a rough guide to true population based need. NIC cot requirements depend critically upon the size of the served population - small populations are subject to greater random variability and require relatively more cots to ensure cot availability on an equivalent proportion of days. $A$ neonatal unit should not therefore serve a population generating fewer than $\mathbf{5 0 0 0}$ births per annum, as relative cot requirements become excessive. For 5000 and 25000 births per annum, the estimated population based provision which would ensure free cots on 29 out of 30 days falls gradually from $1 \cdot 20$ to 0.88 NIC cots per 1000 births per annum. A cooperative network of NICUs offers the opportunity to provide fewer cots per head of population while maintaining good access for most neonates referred to the service.

( $(\mathcal{F}$ Epidemiol Community Health 1995;49:617-628)

It is essential that the provision of neonatal intensive care (NIC) cots meets the true population based requirement for neonatal intensive care. If there are too few NIC cots, neonates who might benefit from intensive car ${ }^{12}$ will be denied access. On the other hand, NIC is expensive ${ }^{3-5}$ and many of the costs remain fixed even when a neonatal intensive care unit (NICU) operates below its full capacity. ${ }^{5}$ It is therefore equally important that the provision of NIC cots is not excessive.

The past two decades have seen four principal reports on the provision of NICU cots in the United Kingdom. ${ }^{6-9}$ Table 1 summarises their relevant recommendations. Although none of the reports was fully accepted and implemented by the government of the day, each had an important impact upon the medical profession and it is perhaps surprising that the hard evidence upon which their recommendations were based is rather scanty. The Short report, ${ }^{8}$ drew upon the results of a study by Simpson and Walker ${ }^{10}$ which monitored the special and intensive care units in the London and University College Hospitals in 1972, 1974, and 1976. The percentage of babies needing NIC in relation to their birth weight was related to the total birth weight distribution of the health region. Assuming an average $70 \%$ cot occupancy, it was estimated that there was a requirement for 57 cots for 
Table 1 Principal British reports and recommendations

\begin{tabular}{|c|c|c|}
\hline Year & Report & Recommendation \\
\hline 1974 & $\begin{array}{l}\text { The Sheldon report }{ }^{6} \\
\text { (Report of the Expert Group on the Special Care of Babies) }\end{array}$ & $\begin{array}{l}0.4 \text { cots per } \\
1000 \text { births }\end{array}$ \\
\hline 1977 & $\begin{array}{l}\text { The BPA/RCOG Liaison Committee report } \\
\text { (Recommendations for the improvement of infant care } \\
\text { during the perinatal period in the UK) }\end{array}$ & $\begin{array}{l}1.0 \text { cots per } \\
1000 \text { births }\end{array}$ \\
\hline 1980 & $\begin{array}{l}\text { The Short report } \\
\text { (Second report from the Social Services Committee) }\end{array}$ & $\begin{array}{l}1.3 \text { cots per } \\
1000 \text { births }\end{array}$ \\
\hline 1988 & $\begin{array}{l}\text { The Royal College of Physicians report } \\
\text { (Medical care of the newborn in England and Wales) }\end{array}$ & $\begin{array}{l}1.5 \text { cots per } \\
1000 \text { births }\end{array}$ \\
\hline
\end{tabular}

BPA $/$ RCOG $=$ British Paediatric Association/Royal College of Obstetricians and Gynaecologists

45763 births - that is, $1 \cdot 2$ cots per 1000 births (or 1.3 per 1000 including neonates born outside the region). The 1988 recommendations of the Royal College of Physicians ${ }^{9}$ were partly based on a reapplication of the same model ${ }^{10}$ to the England and Wales birth weight distribution in 1985. The report also quoted an unpublished study in the North Western Health Region and experience in Bristol referenced to the British Medical fournal. ${ }^{11}$ The relevance of the Bristol reference, however, is limited to the following comment: ${ }^{11}$ "Early experience with the audit in Bristol has already shown that recommendations of one intensive care cot for every 1000 births may be too low. The true requirement seems to be 1.4 cots".

There have also been a number of relevant studies from elsewhere in the world. In 1970, based upon experience in Toronto, Swyer ${ }^{12}$ suggested that the average length of stay in a NIC cot was six days and that one cot could therefore service 60 babies per annum. He argued that most neonates who die are admitted to an NIC at some point and that one third of NIC admissions die. He therefore estimated the number of babies requiring NIC as the neonatal mortality rate (NMR) multiplied by three. The cot requirement per 1000 live births was then obtained as $\mathrm{NMR} \times 3 \div 60$, and given an NMR of 14 per 1000 live births this equated to a requirement for 0.7 cots per 1000 live births. $^{12}$ In 1976, Richardson ${ }^{13}$ reapplied Swyer's formula to a population in California but, given a longer mean stay, revised the formula to NMR $\times 3 \div 35$. In 1978, Morriss et $a l^{14}$ reviewed 1700 admissions to Hermann Hospital in Texas. They estimated transition probabilities into and between low risk care, intermediate care, maximum care, home, and death and used these to generate a simulated data set. Aiming for an $85 \%$ bed occupancy with a $5 \%$ probability of a unit being full, they estimated a need for 65 maximum care cots for a population generating 44000 births - that is, approximately 1.5 cots per 1000 births. ${ }^{14}$

One of the difficulties in interpreting results from different studies is the variation in terminology. In an attempt to standardise terminology, the British Paediatric Association and the British Association of Perinatal Medicine published an article in $1985^{15}$ which defined different levels of critical care for neonates. Intensive care level 1 (ICL1) was defined as a requirement for assisted ventilation or total parenteral nutrition (TPN). Intensive care level 2 (ICL2) was defined as: unstable cardiovascular or respiratory disease; care after major surgery; the first two days after delivery of a baby born before 30 weeks of gestation; convulsions; being transported by NIC staff between hospitals; or undergoing major medical procedures (for example, peritoneal dialysis or cardiac catheterisation). Babies in a variety of less critical states ${ }^{15}$ were considered to be receiving special care.

Using these definitions, Field et $a l^{16}$ monitored the NIC activity in the Trent Regional Health Authority (RHA) between 1 February 1987 and 31 January 1988. The total number of days of ICL1 was observed directly (6336) and the total number of days of ICL2 (8680) was inferred by relating the ratio of ICL1:ICL2 in round-trip transfers to the total number of days of ICL1. During the period of study there were 55692 births in Trent and assuming an arbitrary $70 \%$ bed occupancy, it was estimated that the total NIC cot requirement was approximately $1 \cdot 1$ cots per 1000 births. $^{16}$

In January 1992, ministers of the British government requested that the Clinical Standards Advisory Group should set up advisory groups to, "Advise on access and availability of selected NHS specialist services". NIC was selected as one of four services for special investigation. David Field was on the advisory group, and, recognising the deficiencies of previous work, felt that it was necessary to repeat the Trent study using, where possible, methods that could circumvent some of these problems. This paper describes the design, conduct, and interpretation of the second Trent study. While this study was underway, an independent study was carried out in the Northern RHA ${ }^{17}$ and its findings are so pertinent to a proper interpretation of the Trent study that they will be considered in detail in the Discussion. In common with all of the other studies referred to above, these two studies formally measure utilisation, and hence met demand, rather than true need.

\section{Methods}

\section{STUDY POPULATION}

Trent RHA has a population of 4.6 million people generating approximately 63000 births annually. The region contains a number of cities with large ethnic communities as well as extensive rural areas. In 1990, neonatal services were provided by a total of five tertiary referral centres and 12 other consultant units with a variety of capacities for NIC. Cross boundary flow (either in or out of the region) is relatively unusual and accounts for less than $5 \%$ of all neonates treated.

\section{STUDY DESIGN}

The study ran from 1 January 1990 to 31 March 1992. It investigated all babies admitted to Trent RHA NIC or special care units who fulfilled at least one of the following criteria: birth weight $<1500 \mathrm{~g}$; gestation $<32$ weeks; requiring any active respiratory support other than initial resuscitation; requiring in utero or neonatal transfer for the purposes of receiving high dependency care; severe asphyxial brain insult after delivery; or death. The study in- 
cluded a small number of babies born to Trent residents who met the criteria above and who were cared for in NIC facilities in neighbouring health regions. Babies born to non-resident mothers were excluded from the study. Two research assistants trained in neonatal nursing completed a questionnaire for each baby using information from the clinical notes, NICU information sources, and discussions with staff. Each tertiary referral centre was visited weekly, while smaller units were visited as and when required. The questionnaire collected information pertaining to demography, delivery, NIC admission and discharge, and clinical details including the total number of days of ventilation, constant positive airways pressure (CPAP), supplemental oxygen, and total parenteral nutrition (TPN). A neonate admitted to more than one NIC unit had a questionnaire completed for each unit. Before analysis, all of the questionnaires pertaining to such a neonate were linked together, using a common identification code, to produce a concatenated timeline representing the total NIC experience for that baby.

Primary coding of the total duration of stay at each NICU consisted of a date of admission and a date of discharge. To avoid systematic bias, the total length of stay of a baby admitted and discharged on the same day was estimated to be 0.5 days. For babies admitted and discharged on different days, the total duration was estimated as the difference, in days, between the two dates. This is equivalent to assuming that each baby spent (on average) half a day in the NICU on the day of admission and half on the day of discharge.

ESTIMATING THE DURATION OF ICL1 AND ICL2 The number of days spent by a neonate at ICL1 was obtained by adding up the total number of days spent on a ventilator or receiving TPN. Unfortunately, as ICL2 is relatively poorly defined there was no simple data item which could have been collected that would have unequivocally indicated that a baby was receiving ICL2. Furthermore, attempts to record ICL2 "objectively" ${ }^{16}$ have shown that widely different perceptions of ICL2 exist even when a formal definition is provided. ${ }^{16}$ For these reasons, and to maintain consistency with the previous Trent study, ${ }^{16}$ the relationship between the duration of ICL1 and ICL2 was estimated in those neonates who received "round-trip transfers" (see Appendix A). An equivalent relationship was then presumed to exist in other babies (non-round-trip transfers) who received ICL1. This permitted an estimate of ICL2 duration to be obtained indirectly.

A round-trip transfer is a baby who receives ICL1 at a tertiary referral centre having been transferred (in utero or postnatally) from another hospital in the region and is then transferred back to that same hospital, or to another hospital nearby, once the requirement for NIC has passed. For the purposes of analysis, it was assumed that if a baby was transferred to a tertiary referral centre for ICL1 then all time spent in that unit over and above the time spent at ICL1 was spent at ICL2 (see Discussion). This then provided a direct estimate of ICL2 duration in all round-trip transfers who received ICL1.

The primary record of the duration of ICLl was a variable representing the total number of days upon which the baby was recorded to have received either ventilation or TPN. Before analysis, the total duration of ICL1 was modified in the same manner as total duration (see above) in order to avoid systematic bias arising from the fact that the first and last days of a treatment episode will, in general, be incomplete. For round-trip transfers the total duration of ICL2 was estimated as the difference between the total stay in the tertiary referral centre and the total time spent at ICL1 at that centre. In the case of those few babies who were subject to two or more round-trip transfers, only the first round-trip was used in the process of modelling the relationship between ICL1 and ICL2.

\section{ESTIMATING THE REGIONAL UTILISATION OF NIC} COTS

Having derived a model relating ICL1 to ICL2 (see Appendix A), a value for the estimated duration of ICL2 was imputed, using the model, for each non-round-trip transfer who received ICL1. For babies who had spells of ICL1 in more than one unit, separate estimates of ICL1 and ICL2 were obtained for each unit. If a baby spent a total of 12 days on a unit, of which three were observed to be at ICL1 and two were imputed to be at ICL2, it was assumed, arbitrarily, that the first three days were spent at ICL1, the next two at ICL2, and the remainder on special care. Given the methods used (see below), this assumption would have made little difference to substantive conclusions. In those cases where the sum of ICL1 and imputed ICL2 exceeded the observed total stay in the NICU, a truncation rule was applied and the estimated duration of ICL2 was set exactly equal to the difference between the total length of stay and the duration of ICL1.

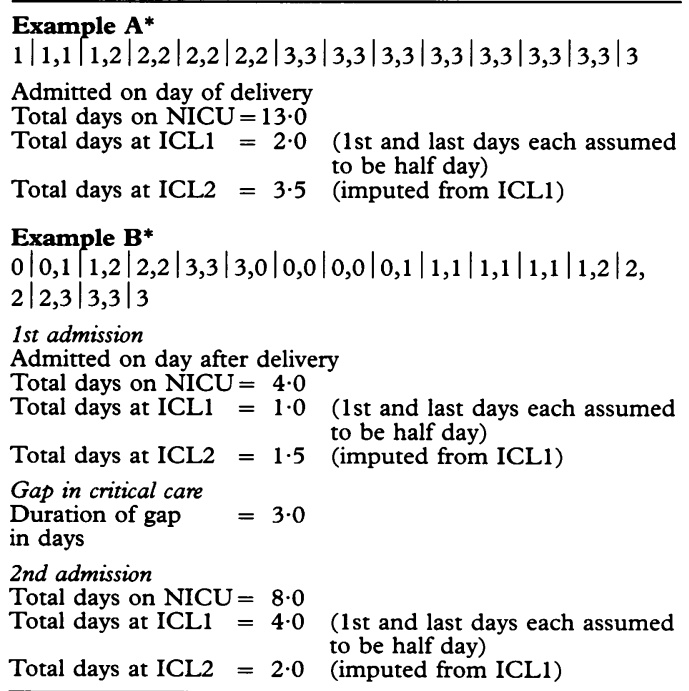

Figure 1 Two illustrative half day time line vectors. 


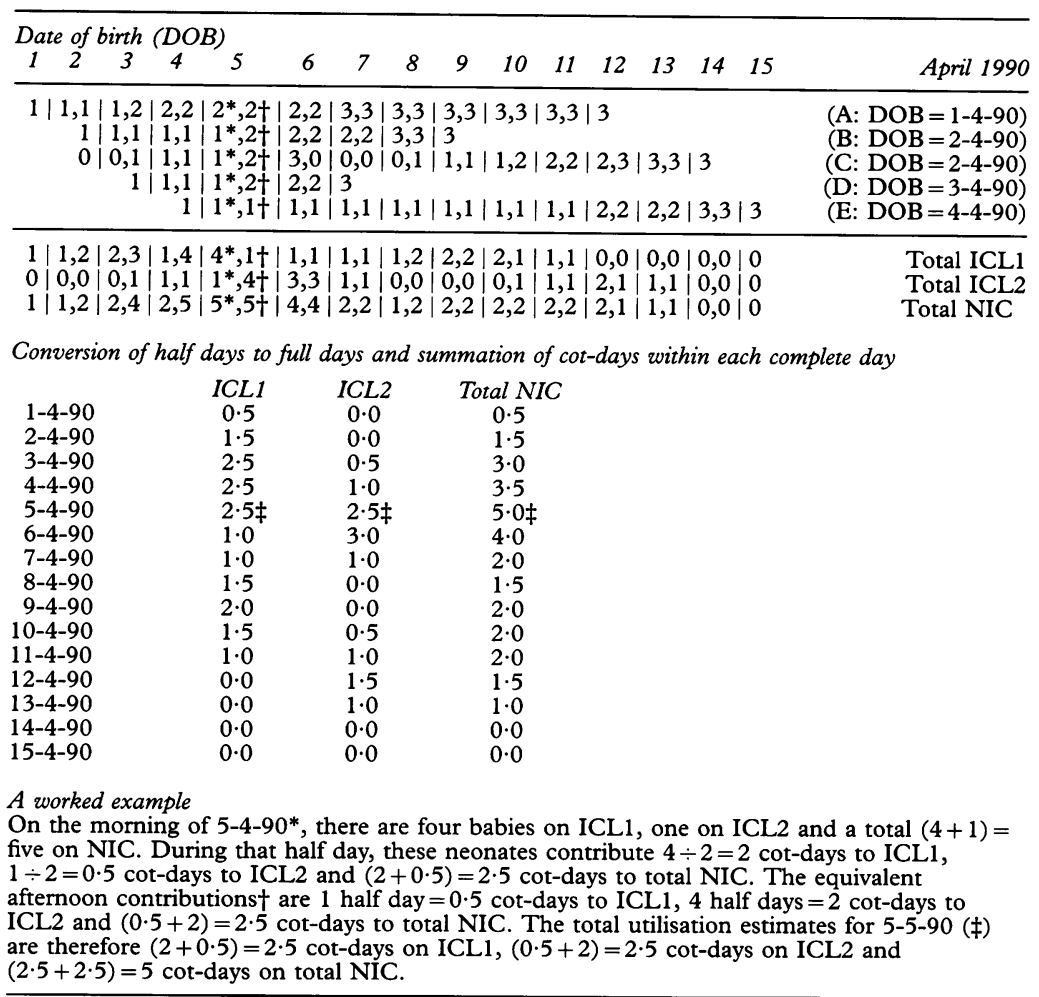

Figure 2 The summation of the time-lines for five hypothetical neonates

Each baby's time-line was converted into a vector of half days. Each half day was coded " 1 " if the baby was considered to be on ICL1 during that half day, " 2 " if the baby was imputed to be on ICL2, and " 3 " if the baby was still on the unit but not receiving NIC. In those babies in whom first admission was delayed, all half days between birth and first admission to a NICU were coded " 0 " as also were all half days which fell during a gap in critical care. These gaps occurred if, for example, a baby was temporarily discharged from a NICU to a normal ward. For the purposes of illustration, figure 1 details two hypothetical time-line vectors. All time-line vectors start on the day of birth. In order to avoid systematic bias, all deliveries were assumed to take place at 12.00 noon.

Having generated time-line vectors for all babies in the study, they were initially aligned by date of birth. Estimates of the half daily utilisation of ICL1 and ICL2 cots were then obtained by summing all equivalent half days across all vectors. Finally, the paired half day utilisation estimates were added to obtain daily estimates of total cot requirements for ICL1, ICL2, and total NIC (ICL1 + ICL2). For a simple illustration see figure 2 .

At the start of the study, the observed cot utilisation will increase as neonates are enrolled into the study. During this phase, the estimated daily utilisation data will underestimate true cot utilisation because a significant proportion of the babies in the NICUs will have been born before the start of the study and will not therefore be included. ICL1, ICL2, and total NIC estimates pertaining to the first 50 days were therefore discarded and although this decision was arbitrary, increasing it to 100 days made almost no difference to the study results. At the end of the study period, as soon as enrolment stops, the estimated cot utilisation will decline, and even though individual neonates may be under continued follow up, all estimates of cot utilisation must be discarded. Utilisation estimates were therefore calculated for the period 21 May 1990 to 31 March 1992 inclusive; a total of 681 days.

\section{ESTIMATING THE POPULATION BASED}

REQUIREMENT FOR NIC COTS

The number of NIC cots required to serve a birth population the size of that in Trent RHA depends upon the frequency with which it is viewed as acceptable for all cots to be full and for neonates to be transferred to neighbouring authorities. For the purposes of analysis, it was decided that it might be acceptable for all cots to be full as often as one day in an average ( 30 day) calendar month but that for a health authority to view itself as self sufficient in NIC cots, it would be unreasonable for all cots to be full more frequently than this. This is equivalent to fulfilling cot requirements on 29 of $30=96 \cdot 7 \%$ of days.

Until recently, ${ }^{17}$ and with one notable prior exception, ${ }^{14}$ most papers which have addressed the issue of cot requirements for NIC have assumed that the required number of cots (per 1000 births) is independent of the size of the population to be served. For example, at 0.8 cots per 1000 births per annum, a population generating 1250 births per annum would require one cot while a population generating 25000 births would need 20 cots.

Unfortunately, this logic is seriously flawed. A small population generating few births will have a greater multiplicative day to day variation in the number of cots required than will a population serving a large population with many births. Thus, in a small population with an average daily requirement for one cot, it would not be particularly surprising if a number of days occurred when three cots were required. On the other hand, in a large population with an average daily requirement for 10 cots, it would be exceedingly unusual for 30 cots to be required. This indicates that if, for example, one was to provide enough cots to meet requirements on $96.7 \%$ of all days, the cot requirement per 1000 births would be rather higher for the smaller population than for the larger one. This issue must be taken into proper account in estimating the population based requirement for NIC cots. In its original form, the study population was therefore used to derive estimated cot requirements for a population generating 63000 births, and a series of Monte Carlo stimulations were used to estimate the cot requirements in smaller populations (see Appendix B).

Two factors determine the number of babies requiring NIC on a given day. ${ }^{18}$ Firstly, the distribution of the number of births of babies requiring NIC in the days preceding the day of interest and secondly, the distribution of the duration of NIC. For the purposes of modelling, these determinants were assumed to be 
Table 2 The observed duration of intensive care level (ICL) 1 and the imputed duration of ICL2 by the type of centre in which the treatment occurred

\begin{tabular}{|c|c|c|c|c|}
\hline Characteristic & $\begin{array}{l}\text { Tertiary NIC } \\
\text { only }\end{array}$ & $\begin{array}{l}\text { Non-tertiary } \\
\text { NIC only }\end{array}$ & $\begin{array}{l}\text { Both tertiary and } \\
\text { non-tertiary NIC }\end{array}$ & $\begin{array}{l}\text { All neonates } \\
\text { receiving NIC }\end{array}$ \\
\hline $\begin{array}{l}\text { No of infants receiving } \\
\text { ICL1 }\end{array}$ & 949 & 579 & 202 & 1730 \\
\hline Total duration of ICL1 (d) & 8179 & $2801 \cdot 5$ & $\begin{array}{l}2006 \text { tertiary } \\
375 \cdot 5 \text { non-tertiary } \\
2381.5 \text { total }\end{array}$ & 13362 \\
\hline $\begin{array}{l}\text { Mean duration of ICL1 } \\
\text { (d) }\end{array}$ & $8 \cdot 62$ & $4 \cdot 84$ & $\begin{array}{l}9.93 \text { tertiary } \\
1.86 \text { non-tertiary } \\
11.79 \text { total }\end{array}$ & $\begin{array}{l}\text { Mean }=7 \cdot 72 \\
\text { Median }=3 \\
\text { Range }=0.5-305\end{array}$ \\
\hline $\begin{array}{l}\text { No of infants receiving } \\
\text { ICL2 }\end{array}$ & 934 & 487 & 69 & 1490 \\
\hline Total duration of ICL2 (d) & 7559 & $3018 \cdot 5$ & $\begin{array}{l}370.5 \text { tertiary } \\
191 \text { non-tertiary } \\
561.5 \text { total }\end{array}$ & 11139 \\
\hline $\begin{array}{l}\text { Mean duration of ICL2 } \\
\text { (d) }\end{array}$ & $8 \cdot 09$ & $6 \cdot 20$ & $\begin{array}{l}5.37 \text { tertiary } \\
2.78 \text { non-tertiary } \\
8 \cdot 15 \text { total }\end{array}$ & $\begin{array}{l}\text { Mean }=7 \cdot 48 \\
\text { Median }=5 \cdot 5 \\
\text { Range }=0 \cdot 5-166\end{array}$ \\
\hline
\end{tabular}

$\mathrm{NIC}=$ neonatal intensive care. $\mathrm{d}=$ days.

Table 3 Birth weight and mortality in relation to site of receipt of neonatal intensive care (NIC)

\begin{tabular}{|c|c|c|c|c|}
\hline Characteristic & $\begin{array}{l}\text { Neonates who received } \\
\text { tertiary ICLI only }\end{array}$ & $\begin{array}{l}\text { Neonates who received } \\
\text { non-tertiary ICL1 only }\end{array}$ & $\begin{array}{l}\text { Neonates who received } \\
\text { both tertiary and non- } \\
\text { tertiary ICL1 }\end{array}$ & $\begin{array}{l}\text { All neonates who } \\
\text { received ICL1 }\end{array}$ \\
\hline Total no & 949 & 579 & 202 & 1730 \\
\hline $\begin{array}{l}\text { Birth weight: } \\
\quad<1000 \mathrm{~g} \\
1000-1499 \mathrm{~g} \\
1500-2499 \mathrm{~g} \\
\geq 2500 \mathrm{~g}\end{array}$ & $\begin{array}{l}217(22 \cdot 9 \%) \\
278(29 \cdot 4 \%) \\
278(29 \cdot 4 \%) \\
174(18 \cdot 5 \%)\end{array}$ & $\begin{array}{r}79(13 \cdot 6 \%) \\
120(20 \cdot 7 \%) \\
225(38 \cdot 9 \%) \\
155(26 \cdot 8 \%)\end{array}$ & $\begin{array}{l}52(25.9 \%) \\
54(26.9 \%) \\
52(25.9 \%) \\
43(21.4 \%)\end{array}$ & $\begin{array}{l}348(20 \cdot 1 \%) \\
452(26 \cdot 2 \%) \\
555(32 \cdot 1 \%) \\
372(21 \cdot 5 \%)\end{array}$ \\
\hline Birth weight missing & 2 & 0 & 1 & 3 \\
\hline $\begin{array}{l}\text { Gestational age: } \\
<32 \mathrm{wk} \\
32-36 \mathrm{wk} \\
\geq 37 \mathrm{wk}\end{array}$ & $\begin{array}{l}565(59 \cdot 5 \%) \\
228(24 \cdot 0 \%) \\
156(16 \cdot 4 \%)\end{array}$ & $\begin{array}{l}257(44 \cdot 4 \%) \\
209(36 \cdot 1 \%) \\
113(19 \cdot 5 \%)\end{array}$ & $\begin{array}{r}120(59 \cdot 4 \%) \\
47(23 \cdot 3 \%) \\
35(17 \cdot 3 \%)\end{array}$ & $\begin{array}{l}942(54 \cdot 5 \%) \\
484(28 \cdot 0 \%) \\
304(17 \cdot 6 \%)\end{array}$ \\
\hline Neonatal death & $204(21 \cdot 5 \%)$ & $106(18 \cdot 3 \%)$ & $44(21 \cdot 8 \%)$ & $354(20 \cdot 5 \%)$ \\
\hline Death before discharge from NIC & $222(23 \cdot 4 \%)$ & $115(19 \cdot 9)$ & $51(25 \cdot 2 \%)$ & $388(22 \cdot 4 \%)$ \\
\hline
\end{tabular}

$\mathrm{ICL}=$ intensive care level.

independent. That is, the distribution of the duration of NIC in neonates born on days in which several other babies requiring NIC were also born was presumed to be the same as that in neonates born on days which no other babies requiring NIC were born. On the basis of this assumption alone, the estimated cot utilisation was obtained by independently sampling the observed data set to obtain the empirical distributions of: (i) the number of babies born on a given day that ultimately require NIC; and (ii) the number of days spent on NIC. See Appendix B for details.

\section{Results}

Between 1 April 1990 and 31 March 1992 there was a total of 126343 live births to residents of Trent RHA. Of these, $402(0 \cdot 32 \%)$

Table 4 A generalised linear model relating intensive care level (ICL) 2 duration to ICL1 duration and gestational age

\begin{tabular}{|c|c|c|c|}
\hline Variable & Coefficient & Standard error & $\begin{array}{l}\text { Likelihood ratio } \%^{2} \text { test } \\
\text { for deletion }\end{array}$ \\
\hline $\begin{array}{l}\text { Constant } \\
\text { Duration } \\
\text { ICL1 (d) } \\
\text { Duration } \\
\text { ICL1 } \\
\text { Duration } \\
\text { ICL1 } \\
\text { Gestation } \\
\text { (wk) } \\
\text { Gestation }^{2}\end{array}$ & $\begin{array}{l}15 \cdot 11 \\
0.1155 \\
-0.003812 \\
0.00003407 \\
-0.7916 \\
0.01128\end{array}$ & $\begin{array}{l}3.060 \\
0.01891 \\
0.0007609 \\
0 \cdot 000007452 \\
0 \cdot 1886 \\
0.002881\end{array}$ & $\begin{array}{l}\chi_{1}^{2}=33 \cdot 3, \\
\mathrm{p}<0 \cdot 0001 \\
\chi_{1}^{2}{ }_{1}=19 \cdot 3 . \\
\mathrm{p}<0 \cdot 0001 \\
\chi_{1}^{2}=15 \cdot 2, \\
\mathrm{p}<0 \cdot 0001 \\
\chi_{1}^{2}=16 \cdot 9, \\
\mathrm{p}<0 \cdot 0001 \\
\chi_{1}^{2}=14 \cdot 7, \\
\mathrm{p}<0.0001\end{array}$ \\
\hline
\end{tabular}

had a birth weight below $1000 \mathrm{~g}$ and a further $725(0.57 \%)$ had a birth weight between $1000 \mathrm{~g}$ and $1499 \mathrm{~g}$. In 1990 , the equivalent percentages $^{17}$ for England and Wales as a whole were $0 \cdot 29 \%$ and $0 \cdot 59 \%$. The overall neonatal death rate in Trent RHA for babies weighing $<1000 \mathrm{~g}$ at birth was 440 per 1000 live births, in those weighing $1000 \mathrm{~g}-1499 \mathrm{~g}$ it was 108 per 1000 live births, and in babies weighing $\geq 1500 \mathrm{~g}$ it was 1.3 per 1000 live births. In England and Wales in 1990, the equivalent rates $^{1719}$ were very similar: 446,88 , and 1.9 per 1000 live births respectively.

During the period of study, $1.4 \%$ (1730) of all neonates born to Trent residents who met the study entry criteria received neonatal intensive care and $1343(77 \cdot 6 \%)$ of these babies survived until their discharge from the NIC system. Among babies weighing $<1000 \mathrm{~g}, 348$ $(77 \%)$ received NIC and of these, $179(51 \cdot 4 \%)$ survived to discharge; $59.0 \%$ (452) of all babies weighing $1000-1499 \mathrm{~g}$ received NIC and 370 $(81.9 \%)$ survived to discharge; $0 \cdot 8 \%$ (927) of all babies weighing $\geq 1500 \mathrm{~g}$ received NIC and $792(85 \cdot 4 \%)$ survived to discharge. Three babies who received NIC had no recorded birth weight, two of these $(66 \cdot 7 \%)$ survived to discharge. Fifty three pairs of siblings and one full set of triplets received ICL1, the remaining 1621 neonates who received ICLl were either singletons, or multiples whose siblings did not receive ICL1. In total $1472(85 \cdot 1 \%)$ neonates 
Table 5 Observed daily cot utilisation for (A) intensive care level 1 (ICL1) and (B) neonatal intensive care (ICL1 +ICL2) in Trent Regional Health Authority between 21 May 1990 and 31 March 1992

\begin{tabular}{|c|c|c|c|c|}
\hline $\begin{array}{l}\text { No of cots used } \\
\text { (A) ICL1 cot ut }\end{array}$ & $\begin{array}{l}\text { No of days upon } \\
\text { which that } \\
\text { utilisation pertained } \\
\text { ation }\end{array}$ & $\begin{array}{l}\% \text { of days upon } \\
\text { which that } \\
\text { utilisation pertained }\end{array}$ & $\begin{array}{l}\text { Cumulative } \\
\text { frequency }\end{array}$ & $\begin{array}{l}\text { Cumulative } \\
\%\end{array}$ \\
\hline $\begin{array}{r}9 \\
10 \\
11 \\
12 \\
13 \\
14 \\
15 \\
16 \\
17 \\
18 \\
19 \\
20 \\
21 \\
22 \\
23 \\
24 \\
25 \\
26 \\
27 \\
28 \\
20 \\
30\end{array}$ & $\begin{array}{r}1 \\
1 \\
8 \\
22 \\
34 \\
33 \\
58 \\
71 \\
77 \\
52 \\
64 \\
49 \\
43 \\
41 \\
37 \\
30 \\
27 \\
17 \\
5 \\
5 \\
4 \\
2\end{array}$ & $\begin{array}{r}0 \cdot 1 \\
0 \cdot 1 \\
1 \cdot 2 \\
3 \cdot 2 \\
5 \cdot 0 \\
4 \cdot 8 \\
8 \cdot 5 \\
10 \cdot 4 \\
11 \cdot 3 \\
7 \cdot 6 \\
9 \cdot 4 \\
7 \cdot 2 \\
6 \cdot 3 \\
6 \cdot 0 \\
5 \cdot 4 \\
4 \cdot 4 \\
4 \cdot 0 \\
2 \cdot 5 \\
0 \cdot 7 \\
0 \cdot 7 \\
0 \cdot 6 \\
0 \cdot 3\end{array}$ & $\begin{array}{r}1 \\
2 \\
10 \\
32 \\
66 \\
99 \\
157 \\
228 \\
305 \\
357 \\
421 \\
470 \\
513 \\
554 \\
591 \\
621 \\
648 \\
665 \\
670 \\
675 \\
679 \\
681\end{array}$ & $\begin{array}{r}0 \cdot 1 \\
0.3 \\
1.5 \\
4 \cdot 7 \\
9 \cdot 7 \\
14 \cdot 5 \\
23 \cdot 1 \\
33 \cdot 5 \\
44 \cdot 8 \\
52 \cdot 4 \\
61 \cdot 8 \\
69 \cdot 0 \\
75 \cdot 3 \\
81 \cdot 4 \\
86 \cdot 8 \\
91 \cdot 2 \\
95 \cdot 2 \\
97 \cdot 7 \\
98 \cdot 4 \\
99 \cdot 1 \\
99 \cdot 7 \\
100 \cdot 0\end{array}$ \\
\hline \multicolumn{5}{|c|}{ (b) NIC (ICL1+ICL2) cot utilisation } \\
\hline $\begin{array}{l}21 \\
22 \\
23 \\
24 \\
25 \\
26 \\
27 \\
28 \\
29 \\
30 \\
31 \\
32 \\
33 \\
34 \\
35 \\
36 \\
37 \\
38 \\
39 \\
40 \\
41 \\
42 \\
43 \\
44 \\
45 \\
46 \\
47 \\
48\end{array}$ & $\begin{array}{r}2 \\
7 \\
5 \\
5 \\
8 \\
18 \\
21 \\
35 \\
43 \\
48 \\
62 \\
44 \\
50 \\
44 \\
42 \\
32 \\
50 \\
27 \\
25 \\
33 \\
35 \\
15 \\
11 \\
11 \\
2 \\
3 \\
2 \\
1\end{array}$ & $\begin{array}{l}0 \cdot 3 \\
1 \cdot 0 \\
0 \cdot 7 \\
0 \cdot 7 \\
1 \cdot 2 \\
2 \cdot 6 \\
3 \cdot 1 \\
5 \cdot 1 \\
6 \cdot 3 \\
7 \cdot 0 \\
9 \cdot 1 \\
6 \cdot 5 \\
7 \cdot 3 \\
6 \cdot 5 \\
6 \cdot 2 \\
4 \cdot 7 \\
7 \cdot 3 \\
4 \cdot 0 \\
3 \cdot 7 \\
4 \cdot 8 \\
5 \cdot 1 \\
2 \cdot 2 \\
1 \cdot 6 \\
1 \cdot 6 \\
0 \cdot 3 \\
0 \cdot 4 \\
0 \cdot 3 \\
0 \cdot 1\end{array}$ & $\begin{array}{r}2 \\
9 \\
14 \\
19 \\
27 \\
45 \\
66 \\
101 \\
144 \\
192 \\
254 \\
298 \\
348 \\
392 \\
434 \\
466 \\
516 \\
543 \\
568 \\
601 \\
636 \\
651 \\
662 \\
673 \\
675 \\
678 \\
680 \\
681\end{array}$ & $\begin{array}{r}0 \cdot 3 \\
1 \cdot 3 \\
2 \cdot 1 \\
2 \cdot 8 \\
4 \cdot 0 \\
6 \cdot 6 \\
9 \cdot 7 \\
14 \cdot 8 \\
21 \cdot 1 \\
28 \cdot 2 \\
37 \cdot 3 \\
43 \cdot 8 \\
51 \cdot 1 \\
57 \cdot 6 \\
63 \cdot 7 \\
68 \cdot 4 \\
75 \cdot 8 \\
79 \cdot 7 \\
83 \cdot 4 \\
88 \cdot 3 \\
93 \cdot 4 \\
95 \cdot 6 \\
97 \cdot 2 \\
98 \cdot 8 \\
99 \cdot 1 \\
99 \cdot 6 \\
99 \cdot 9 \\
100 \cdot 0\end{array}$ \\
\hline
\end{tabular}

Table 6 The total number of neonatal intensive care cots (ICL1+ICL2) needed to meet population based requirements on between $50 \%$ and $99 \%$ of all days

\begin{tabular}{|c|c|c|c|c|c|}
\hline $\begin{array}{l}\text { No of } \\
\text { births }\end{array}$ & $\begin{array}{l}\text { To meet needs } \\
\text { on } 50 \% \text { of days }\end{array}$ & $\begin{array}{l}\text { To meet needs } \\
\text { on } 75 \% \text { of days }\end{array}$ & $\begin{array}{l}\text { To meet needs } \\
\text { on } 90 \% \text { of days }\end{array}$ & $\begin{array}{l}\text { To meet needs } \\
\text { on } 95 \% \text { of days }\end{array}$ & $\begin{array}{l}\text { To meet needs } \\
\text { on } 99 \% \text { of days }\end{array}$ \\
\hline $63000 *$ & 33 & 37 & 41 & 42 & 45 \\
\hline $63000 t$ & 33 & 38 & 41 & 43 & 47 \\
\hline 25000 & 13 & 15 & 19 & 21 & 24 \\
\hline 20000 & 11 & 14 & 16 & 17 & 19 \\
\hline 15000 & 8 & 10 & 12 & 14 & 16 \\
\hline 12000 & 7 & 8 & 10 & 11 & 14 \\
\hline 10000 & 6 & 7 & 9 & 10 & 12 \\
\hline 9000 & 5 & 6 & 8 & 9 & 11 \\
\hline 8000 & 5 & 6 & 7 & 8 & 11 \\
\hline 7000 & 4 & 5 & 6 & 8 & 10 \\
\hline 6000 & 3 & 4 & 6 & 6 & 7 \\
\hline 5000 & 2 & 3 & 4 & 5 & 6 \\
\hline 4000 & 2 & 3 & 4 & 5 & 6 \\
\hline 3000 & 1 & 2 & 3 & 4 & 5 \\
\hline 2000 & 1 & 2 & 3 & 3 & 4 \\
\hline 1000 & 0 & $\overline{1}$ & 1 & 2 & 3 \\
\hline
\end{tabular}

* Observed data; $t$ simulated data. centres only; (ii) non-tertiary referral units only; (iii) care received in both tertiary and nontertiary referral centres. Table 3 details the distributions of birth weight and gestational age and the mortality experience of neonates in the three categories. As might have been expected, there was significant evidence of both birth weight and gestational age heterogeneity across the three caregories $\left(\chi_{6}^{2}=53.9\right.$, $\mathrm{p}<0.0001$ and $\chi_{4}^{2}=38.7, \quad \mathrm{p}<0.0001$ respectively). This arose principally because babies in the second category were less likely to fall into the lower birth weight and gestational age groups. There was no significant birth weight or gestational age heterogeneity between the first and third categories $\left(\chi_{3}^{2}=\right.$ $2.47, \mathrm{p}=0.48$ and $\chi_{2}^{2}=0.12, \mathrm{p}=0.94$ respectively). There was no significant evidence of heterogeneity across the three categories for either neonatal mortality $\left(\chi_{2}^{2}=2 \cdot 49, \mathrm{p}=0 \cdot 29\right)$ or deaths before discharge from NIC $\left(\chi_{2}^{2}=\right.$ $3 \cdot 62, \mathrm{p}=0 \cdot 16)$.

Sixty three $(3.6 \%)$ of the Trent resident neonates receiving NIC were born outside Trent RHA. A total of 24 neonates $(1 \cdot 4 \%)$ received 170.5 days of ICL1 outside Trent RHA. Nine neonates $(0.5 \%)$ received all of their ICL1 outside Trent RHA; a total of 53.5 days. Babies in this last group were at risk of being missed by the study and on past experience we probably identified only $50 \%$ of them. However, the magnitude of this error $(<0.5 \%)$ would have been negligible compared with other sources of potential error (see Discussion).

IMPUTING THE DURATION OF ICL2

In total, there were 243 round trip transfers. Table 4 details the coefficients of the generalised linear model that was used to impute the duration of ICL2 (see Appendix A). It was found that the expected duration of ICL2 was a non-linear function of gestational age and duration of ICL1. Having modelled the duration of ICL1 and gestational age, it was found that terms in birth weight provided no significant contribution to the fit of the model $\left(\chi^{2}{ }_{1}=0.35, p=0.55\right.$ for inclusion of a linear term in birth weight, $\chi_{1}^{2}=1 \cdot 78, p=0.18$ for a quadratic term). The model was shown to provide an acceptable fit to the observed data.

On the basis of the model, and applying the truncation rule referred to under Methods, table 2 details the estimated total number of days and the estimated mean duration of ICL2 both overall and categorised by the type of centre in which treatment was imputed to have been received. Four babies were imputed to have ICL2 durations in excess of 1000 days, that is: 103 days, $117 \cdot 5$ days, 130 days and 166 days. In order to ensure that the model was not producing irrational estimates in these particular neonates their time-lines were studied individually. The duration of ICLl received by the four cases (and their gestational ages) were 172 days ( 28 weeks), 83 days ( 27 weeks), 118 days ( 31 weeks), and 103 days ( 27 weeks) respectively; thus rendering the ICL2 estimates apparently reasonable. 

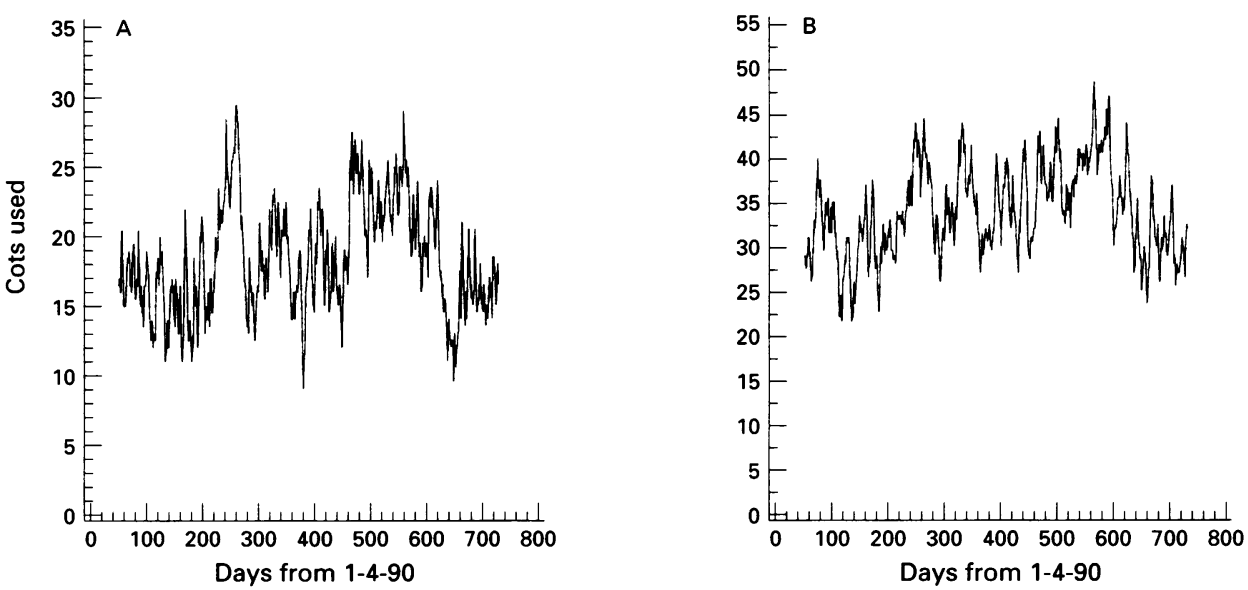

Figure 3 (A) Observed daily intensive care level 1 cot utilisation in Trent Regional Health Authority (RHA), 21 May 1990 to 31 March 1992. (B) Observed daily neonatal intensive care unit (intensive care levels $1+2$ ) cot utilisation in Trent RHA, 21 May 1990 to 31 March 1992.

ESTIMATING THE UTILISATION OF ICL1 AND ICL2 IN TRENT RHA

Figure 3(A) details the observed day to day utilisation of ICL1 cots in Trent RHA between 21 May 1990 and 31 March 1992 inclusive (see Methods). Figure 3(B) details the equivalent imputed day to day utilisation of all NICU cots (ICL1 and ICL2 combined). Tables 5(A) and 5 (B) provide the equivalent information in tabular form. Thus, on the basis of table 5(B), if Trent RHA provided a total of 33 NICU cots, it would have met its population based demand on a total of 348 days out of $681=51 \cdot 1 \%$ of days. Similarly, if there were a total of 43 NICU cots in Trent, these would have met requirements on $97 \cdot 2 \%$ of all days during the study period and would therefore have been adequate to ensure that cot requirements were met on 29 days $(96.7 \%)$ in an average 30 day month (see Methods).

On the basis of the Monte Carlo simulations, table 6 details the estimated number of NICU cots needed to meet requirements on between $50 \%$ and $99 \%$ of all days for a range of populations generating between 1000 and 63000 births per annum. For each population size, three simulations of 10 years' worth of data were generated. In each case the three simulations were very similar to one another but for the purposes of presentation, the tabulations are based solely upon the simulation that led to intermediate results.

Table 7 shows the number of cots needed to meet requirements on $96.7 \%$ of days. It details the total number of NICU cots required for each population size and expresses this both as a number and also as a rate (number of cots per 1000 births per annum). In addition, it details the equivalent figures for ICL1 cots alone. It is evident that, when expressed as a rate per 1000 births, the number of cots needed to meet requirements on $96.7 \%$ of days increases considerably as the served population decreases in size. Thus, in order to meet its total NICU requirements on $96.7 \%$ of days, a health authority with a population generating only 1000 births would need to provide 2 cots ( 2 cots per 1000 births), while a health authority generating 12000 births would need to provide 12 cots ( 1 cot per 1000 births). On the other

Table 7 The total number (and rate per 1000 births) of cots at intensive care level 1 and total neonatal intensive care unit needed to meet apparent population based requirements on at least $96 \cdot 7 \%$ of all days

\begin{tabular}{|c|c|c|c|c|c|}
\hline $\begin{array}{l}\text { No of } \\
\text { births }\end{array}$ & $\begin{array}{l}\text { No of } \\
\text { ICL1 cots }\end{array}$ & $\begin{array}{l}\text { Cots per } \\
1000 \text { births }\end{array}$ & $\begin{array}{l}\text { Total no of } \\
\text { NICU cots }\end{array}$ & $\begin{array}{l}\text { Cots per } \\
1000 \text { births }\end{array}$ & $\begin{array}{l}\text { Informal uncertainty range* for } \\
\text { rate of total NICU cots }\end{array}$ \\
\hline $63000 t$ & 26 & 0.41 & 43 & 0.68 & 0.59 to 0.78 \\
\hline $63000 \ddagger$ & 27 & 0.43 & 44 & $0 \cdot 70$ & 0.61 to 0.81 \\
\hline 25000 & 13 & 0.52 & 22 & $0 \cdot 88$ & 0.77 to 1.01 \\
\hline 20000 & 11 & 0.55 & 18 & 0.90 & 0.78 to 1.04 \\
\hline 15000 & 9 & $0 \cdot 60$ & 14 & 0.93 & 0.81 to 1.07 \\
\hline 12000 & 8 & 0.67 & 12 & 1.00 & 0.87 to 1.15 \\
\hline 10000 & 7 & $0 \cdot 70$ & 10 & 1.00 & 0.87 to 1.15 \\
\hline 9000 & 6 & 0.67 & 9 & 1.00 & 0.87 to 1.15 \\
\hline 8000 & 6 & 0.75 & 9 & $1 \cdot 13$ & 0.98 to 1.30 \\
\hline 7000 & 5 & 0.71 & 8 & $1 \cdot 14$ & 1.99 to 1.31 \\
\hline 5000 & 4 & 0.75 & 6 & $1 \cdot 20$ & 1.04 to 1.38 \\
\hline 4000 & 3 & 1.00 & 5 & $1 \cdot 25$ & 1.09 to 1.44 \\
\hline 3000 & 3 & 0.67 & 4 & $1 \cdot 33$ & 1.16 to 1.53 \\
\hline 2000 & 2 & $1 \cdot 00$ & 3 & $1 \cdot 50$ & 1.30 to 1.73 \\
\hline 1000 & 1 & $1 \cdot 00$ & 2 & $2 \cdot 00$ & 1.74 to 2.30 \\
\hline
\end{tabular}

† Observed data.

$\mp$ Simulated data.

* See Discussion page 19 
hand, if a health authority could provide a coordinated service across a region generating 63000 births (such as in Trent), the total NICU cot requirement would only be $43(0.68$ cots per 1000 births).

As a relevant comparison, if one chose to base an estimate of cot requirements upon the mean observed cot utilisation $(33.5$ cots per day) and to aim, as others have done, ${ }^{68-1016}$ for an average $70 \%$ cot occupancy, the estimated cot requirement would have been 0.76 per 1000 births (that is, $33.5 \div\{63 \times[70 / 100]\}$ ) which would ensure cot availability (see table 6 ) on more than $99 \%$ of days for a served population generating 63000 births per annum $(0.76 \times 63 \approx 48$ cots $)$ but would mean that neonates would have to be transferred elsewhere on at least one day in 10 for served populations generating 25000 or fewer births per annum $(0.76 \times 25 \approx 19$ cots $)$ and one day in four in populations generating 4000 or fewer births per annum $(0.76 \times 4 \approx 3$ cots $)$.

\section{Discussion}

While our analysis may seem to estimate the population based requirement or need for NIC cots, in reality it reflects the observed utilisation of NIC cots in Trent. If, in practice, the Trent Region is grossly underprovided for NIC cots and a large number of neonates are consequently denied access, the observed utilisation may be an important underestimate of the true requirement. Conversely, if the provision of NIC cots in Trent is excessive the observed utilisation may overstate true need. This problem is intrinsic to all studies that attempt to estimate population based requirements from observed utilisation data, 10141617 and it means that such studies only provide a useful pointer to the true population based requirement for NIC cots if one is prepared to assume that the utilisation of cots in the population under study is clinically appropriate at a population level.

To investigate this issue further, a series of additional Monte Carlo simulations were performed. If Trent RHA were truly underprovided for NIC cots, one might anticipate that at times of heavy utilisation there would be a tendency for NICUs to attempt to discharge babies more rapidly to clear cots. This would attenuate the upward spikes on the observed distribution of cot utilisation (see figure 3A). If, however, the Monte Carlo approach were used to simulate a population generating 63000 births, there would then be no systematic attenuation of upward spikes. In practice, it was found that the upward spikes in the stimulated data were similar to those in the observed data (compare also the observed and simulated cut points for a population generating 63000 births in table 6) and it therefore seems unlikely that workload limitations could have had any major impact upon the principal inferences arising from the study. Similarly, there was little evidence of inappropriate overutilisation.

As an additional check, a series of Monte Carlo simulations were carried out in which the time-lines of babies born at times of overall very high workload ( $>42$ babies receiving intensive care in Trent) or very low workload ( $<26$ babies receiving intensive care in Trent) were excluded from the analysis. For a simulated population generating 63000 births the estimated number of cots required to ensure access on at least $96 \cdot 7 \%$ of days remained at 44 and the requirements for simulated populations generating $5000,10000,12000,15000$ and 20000 births all changed by one cot or less in either direction.

While the Trent study was in progress, a second independent study was carried out in the Northern Health Region. ${ }^{17}$ Using an analysis based upon the assumption that the "daily demand for (emergency) beds may be statistically represented by the Poisson distribution", ${ }^{17}$ the Northern Health Region study concluded that in a population generating a total of approximately 39000 births, a single regional NICU (or a flexible and collaborative network of five NICUs) providing 31 NIC cots should be able to fulfil, on "all but three or four days of the year", ${ }^{17}$ that part of the requirement for "high dependency care" which is currently fulfilled by the five referral units in the region. Although the principal results of the paper ${ }^{17}$ were based upon an analysis restricted to the neonates treated in the five referral centres, it is possible to use the stated methods of the paper to estimate the cot requirement for the served population as a whole. If an analysis is based upon the 8696 cot-days reported for all neonatal units combined ${ }^{17}$ it may be estimated, using the cumulative distribution function for the Poisson distribution with a mean of $23.82(8696 \div 365)$, that a total of 35 cots would ensure availablity on 361 days out of 365 in an average year. Using the Monte Carlo simulation approach for a population of size 39000 and adopting a cut point of $98.9 \%$ availability (cots available on all days but 4 in an average year) our method predicted a requirement for 33 cots. Translated to a population generating 39000 births followed for 1 year, the neonates in the Trent study generated the equivalent of 4135 cot-days of ICL1, 3447 cot-days of ICL2, 7582 cot-days of NIC, and an ICL1:ICL2 ratio of $1 \cdot 20: 1$. The equivalent figures from the Northern Health Region study are 4686 cot-days (dependency category " $A$ " care), 4010 cot-days (dependency category " $B$ " care), 8696 cot-days (" $A$ " + " $B$ ") and a ratio ("A":" $B$ ") of $1 \cdot 17: 1$. These results are remarkably similar. However, although the estimates of cot-days are similar in the two studies, the mean duration of NIC was longer in the Trent study (14.2 days) than in the Northern Health Region study ( 9.0 days); one unit in the latter study recorded a mean duration of $14 \cdot 1$ days. ${ }^{17}$ The relevance of these findings are unclear.

The two studies have different strengths and weaknesses. The weakest feature of the Trent study is the inability to observe ICL2 directly, and the consequent need to impute ICL2 duration by extrapolating the relationship between observed ICL1 and assumed ICL2 in roundtrippers to non-round trippers. This process has a number of potential flaws. Firstly, the 
assumption that all the time spent by a round tripper in a tertiary referral centre that is not ICL1 is ICL2 may be wrong. Secondly, this approach makes it impossible to identify babies that received ICL2 alone. Thirdly, round-trippers may be unrepresentative of the general NIC population. Fourthly, the model relating ICL1 duration to ICL2 duration could be incorrect (as any mathematical model may be). Finally, by choosing to truncate the predicted ICL2 duration in those cases where observed ICL1 duration plus predicted ICL2 duration exceeded the total observed time in neonatal intensive care, one might argue that the truncated predictions will be biased downwards. However, it may equally be argued that the truncated data more faithfully reflects what was actually observed.

Although the approach used to estimate ICL2 duration invokes a number of important assumptions, it is based upon a strong logical foundation. Because of resource limitations in tertiary referral centres, such units have a vested interest in the rapid outward transfer of babies who no longer require NIC and may suitably be managed, closer to home, in a hospital that does not necessarily contain a tertiary referral centre. It is therefore probable that a baby on a round-trip transfer will be returned to his or her referring hospital as soon as reasonably possible, once the need for ICL2 has passed. On the other hand, because of the difficulty of readmission, a tertiary referral centre is unlikely to attempt to transfer a round-trip baby too early, even though the same unit might be willing to take the risk of transferring out (to the wards or to special care) an equally sick inborn child in the knowledge that rapid readmission would be possible should a problem occur. For these reasons it would seem unlikely that the first "potential flaw" (see above) is a serious problem. Secondly, it is likely that the majority of days of ICL2 do occur in babies who also receive ICL1 and the impact of the second "potential flaw" is therefore likely to be small. Thirdly, for the purposes of the analysis, given that ICLl and gestation both appear in the predictive model for ICL2, it does not necessarily matter that round trippers had a generally more severe course than non-round trippers (mean duration of $\mathrm{ICL} 1=11.33$ days $v 7 \cdot 10$ days, total stay in a NICU $=56 \cdot 24$ days $v 32.91$ ), the important assumption is that given a specific gestation and a particular duration of ICL1, the associated duration of ICL2 should be the same in round-trippers as in nonround-trippers. In this regard, it is relevant to note that in round-trippers the proportion of total time spent on ICL1 is $20 \cdot 1 \%(11 \cdot 33$ / $56 \cdot 24)$ whereas for non-round-trippers who received ICL1 the equivalent proportion is $21 \cdot 6 \%$. This suggests, but does not prove, that it is unlikely that round-trippers are seriously unrepresentative for the relationship between ICL1 and ICL2. Fourthly, in order to investigate the sensitivity of conclusions to misspecification of the modelled relationship between ICL1 and ICL2, the analysis was repeated having first multiplied, and then divided, the imputed duration of ICL2 by a factor of $1 \cdot 5$. Having carried out the multiplication, the estimated NICU cot requirements for a simulated population generating 12000 births per annum rose from 12 cots $(1.00$ cots per 1000 births) to 13 cots $(1.08$ cots per 1000 births) and the effect of the division was to reduce apparent requirements to 10 cots $(0.83$ cots per 1000 births). Similarly, the effect of repeating the analysis without ICL2 truncation was to increase the estimated requirement for NICU cots in a population generating 12000 births per annum to $14(1.17$ cots per 1000 births). Thus, substantive conclusions would not seem to be critically sensitive to realistic levels of model misspecification, although it is clear that there may be a quantitative impact upon precise inferences and this should not be ignored.

In addition to the uncertainty arising from the unknown influence of analytical assumptions, the potential influence of random variability must also be considered. On the basis of a series of 500 Monte Carlo simulations, each generating 681 days of data for a population producing 63000 births (that is, a series of Monte Carlo simulations each equivalent in structure to the original observed data set), the estimated number of cots required to ensure cot availability on at least $96 \cdot 7 \%$ of days was found to fall between 40 and 48 in $95 \%$ of simulations; this represents a "boot straps" approach to the estimation of a $95 \%$ confidence interval. This range is narrower than the limits of 38 and 50 that were obtained in the sensitivity analysis when the estimated ICL2 duration was divided and multiplied by 1.5 .

The multiplication and division of the model based estimate of ICL2 by a factor of 1.5 is equivalent to multiplying and dividing total cot requirements by $1 \cdot 15$. Thus, for a population generating 63000 births, the multiplicative variability in total cot requirement induced by multiplying and dividing ICL2 duration by 1.5 was $(50 / 38)^{1 / 2} \approx 1 \cdot 15$ and for a population generating 12000 births it was $(13 / 10)^{1 / 2} \approx 1 \cdot 14$. If this magnitude of multiplication/division provides a fair and realistic representation of the true uncertainty in the analysis, the point estimates in column 4 in table 7 may reasonably be translated into "informal uncertainty ranges" by multiplying and dividing each by $1 \cdot 15$ (see table 7 , column 5 ). Although this choice of multiplier is arbitrary, it leads to uncertainty ranges that are more conservative (wider) than standard $95 \%$ confidence intervals.

If there is a weakness in the Northern Health Region approach it is perhaps the assumption that the distribution of daily cot utilisation is Poisson. ${ }^{17}$ Although this assumption is reasonable for independent singular events such as admissions to an emergency ward, ${ }^{18}$ if individual patients remain on the ward for several days it does not follow that the day to day bed utilisation in that unit as a whole will be Poisson distributed unless one makes certain assumptions about the distribution of the length of stay. For this reason, when analysing the day to day distribution of bed occupancy, it is usual (as in our analysis) to consider the distribution 
of length of stay separately from the distribution of admissions. ${ }^{18}$ The motivation for the Poisson distribution is a series of events arising independently with low probability at each of a series of points in time or space. ${ }^{20} \mathrm{Un}$ fortunately, the requirement for independence is not met in the case of the day to day occupation of NICU cots, not only because of the correlation of utilisation from one day to the next, but also because of the fact that siblings who require NIC are likely to require treatment at the same time and the distribution of the number of neonates starting therapy on a given day will not therefore be strictly Poisson. However, although the Poisson distribution may not provide a good theoretical representation of the utilisation of NICU cots on a day to day basis, if one is simply interested in a point estimate of the total proportion of days upon which a given total number of cots is required, it is likely that Poisson based inferences will be reasonably similar to those arising from the true distribution. ${ }^{21}$ This would not be true if the simultaneous treatment of siblings were common or if the follow up time were short. In our data, a Poisson based analysis generated an estimated requirement for 44 cots, rather than the original 43 , in order to satisfy requirements on 29 days $(96 \cdot 7 \%)$ out of 30 .

Given the different categorisation systems used in the Northern RHA study ${ }^{17}$ and our own, it is relevant to contrast the classifications and to consider how inherent differences may have influenced comparisons between the two studies. Very few neonates received TPN in the absence of respiratory support, and hence the Northern Region's category " $A$ " ("Infants requiring artificial respiratory support") was similar to ICL1 in the Trent study. However, the Northern Region's category " $B$ " was somewhat broader than ICL2 and would, for example, have included some babies who never received category " $A$ " care. On the other hand, the Northern Region study excluded babies being treated surgically, whereas surgical cases comprised $6 \%$ of the total ICL1 utilisation in our study. Thus, we believe that the two studies are very comparable with regard to the sickest babies requiring the most high dependency care but that differences may exist in babies who are less seriously ill. If two studies make different, but reasonable, assumptions at the margins and yet produce similar answers, it is likely that these assumptions are not critical and this may be considered to strengthen the inferences that may reasonably be drawn from both studies.

It is clear, both theoretically and from the observed results of our study, that decisions pertaining to the provision of NIC cots must take into account the conflicting requirements of ease of access and economies of scale; a balance which may vary considerably, for example, between an inner city setting and a remote rural community. However, it would seem from our results (see table 7) that cot requirements per 1000 births to meet demand on at least $96.7 \%$ of days are not hugely dissimilar for units serving populations generating between 5000 and 25000 births per annum. Given that ease of access is likely to start being a problem for a single unit serving a population in excess of 25000 births per annum and given that cot requirements start to rise rapidly for single units serving birth populations below 5000 per annum we would recommend that, unless special circumstances pertain, it would be unwise to plan for a single unit serving birth populations outside this range. However, there would seem to be wide scope for manoeuvre within these limits to best fit local circumstances. Alternatively, a cooperative network of units distributed across a larger population (as proposed by the Northern RHA report ${ }^{17}$ ) will take maximum advantage of the economies of scale while ensuring ease of access for most babies.

\section{Summary and recommendations}

Although there are a number of important assumptions built into our analysis, we believe that our estimates are reasonably close to the truth. This viewpoint is supported by the fact that, despite the different strengths and weaknesses of the two studies, our findings are very similar to those from the Northern Region study. ${ }^{17}$ During the period of study, the birth weight distribution and the birth weight-specific neonatal mortality rates in Trent RHA were similar to those in England and Wales as a whole. It was demonstrated that it is unlikely that Trent is seriously under-resourced for neonatal intensive care cots or that Trent NIC facilities are being inappropriately overused. It therefore seems likely that the heterogeneous population of Trent RHA is reasonably representative of the population of England and Wales as a whole and that the utilisation of neonatal cots in Trent does provide a reasonable guide to true population based need. We therefore believe that these data may rationally be used by other Health Authorities as a rough guideline to their own requirement for NICU cots.

Our specific recommendations are:

(1) Because of the excessive day to day variability of utilisation in small populations, it would be unwise, unless other issues are paramount (for example, extreme population sparsity), for a single unit to serve a population generating $<5000$ births per annum.

(2) Tables 6 and 7 may be used by other health authorities as a rough guide to their requirements for NICU cots. Those using the tables are advised to consider the assumptions we made in our analysis (see Discussion), to remember that the study was based upon utilisation data, and to draw conclusions with appropriate care.

(3) If actual cot provision falls outside the indicative ranges, in particular if it is too low, there would be good grounds for investigating whether the local provision of NIC cots appropriately meets local need and demand.

(4) A cooperative NICU network serving a large population, as proposed by the 
Northern RHA study, ${ }^{17}$ may be the best way to strike a balance between ease of access and the advantages arising from the economies of scale.

(5) The formal definition of ICL2 might usefully be modified to generate a universal standard for non-ICL1 high dependency care that can be observed directly. The nursing dependency scale utilised in the Northern RHA study is said to constitute a "replicatable and validated means of identifying those babies who not only generate substantially more ... nursing work ... but also most of the need for technically skilled nursing care"17 and might form the basis of such a definition.

\section{Appendix A}

MODELLING THE RELATIONSHIP BETWEEN ICL1 AND ICL2

As in the previous Trent study, ${ }^{16}$ the distributions of both ICL1 and ICL2, in the round trip transfers, were found to be distributed with a pronounced right hand skew and an approximately constant coefficient of variation. There were a number of babies with an estimated ICL2 duration of zero days. ICL2 duration was therefore modelled by adding a small increment $(0.01$ days), to remove the zeros, and using generalised linear modelling with a gamma error and $\log _{\mathrm{e}} \operatorname{link}^{22}$ A standard model of this type cannot be fitted when the observed response vector includes zeros. The option of using a $\log _{e}(x+k)$ transformation and treating the transformed data as normal was rejected because the model was too sensitive to the value $(\mathrm{k})$ chosen to remove the zeros. In particular, small values of $k$ produced a poorly fitting model strongly influenced by the babies observed to have zero days of ICL2. All modelling was carried out in GLIM 3.77. ${ }^{23}$ Model construction proceeded systematically. The scale parameter was fixed at the value of the moment estimate of dispersion (Pearson $\chi^{2} \div$ residual degrees of freedom) about an appropriate full model. ${ }^{22}$ Where appropriate, statistical significance tests were based upon the likelihood ratio test. ${ }^{22}$. Goodness of fit was adjudged in a standard manner ${ }^{22}$ by: (i) the need for additional polynomial or interaction terms; (ii) the distribution of Pearson residuals; and (iii) an investigation of observations with heavy leverage as indicated by the hat matrix.

\section{Appendix B \\ GENERATION OF A SIMULATED DATA SET \\ Start at simulated day $s=1$}

Stage 1: Randomly sample - with replacement - one day from the period of study and determine how many sibships $\left(n_{1}\right)$ were born on that day.

Stage 2: Randomly sample - with replacement $-\mathrm{n}_{1}$ sibships from all sibships in the observed data set.
Stage 3: Write out the observed time-line vectors for all babies in the $n_{1}$ sibships, aligning them as if they had all been born on day 1 .

\section{Move on to simulate day $s=2$}

Select another day at random. Determine the number $\left(n_{2}\right)$ of sibships born on that day. Randomly sample $n_{2}$ sibships from the observed data set. Write out the observed time-line vectors for all babies in the $\mathrm{n}_{2}$ sibships, aligning them as if they were all born on day 2 .

Continue this process until a random data set has been created which spans a prespecified duration of time (for example, $s=3653$ days $=$ 10 years).

Stage 4: Sum across equivalent half-days in the simulated data set, in the same way as in the real data set (see figure 2).

Stage 5: Discard the cot utilisation estimates for days 1 to 50 and from day 3654 onwards (see Methods).

This simulation provides an estimate of the expected distribution of cot utilisation in a population generating the same number of births as the original study population; that is, 63000 births per annum. To simulate the daily cot requirements of a population generating $B$ births per annum $(B \leq 63000)$ add an additional sampling subroutine to stage 2 . Namely, randomly sample $n_{j}$ sibships on the $j^{\text {th }}$ day, but before each sibship may enter the analysis, it must pass a second test, wherein a random uniform real number (U) between 0.000 and 1.000 is generated and the sibship is only accepted if $U<B / 63000$.

Sibships rather than babies were used as the sampling unit in stage 2, because the NIC cot requirements of, for example, two twins are likely to be correlated with one another. Consequently, if siblings had been separated in the analysis, the simulated distribution would have been somewhat attenuated with flattened peaks and troughs.

We thank all the medical, nursing, and administrative staff of the perinatal units involved in the study, without whose help this work would not have been possible. We thank Dr Jennifer Kurinczuk for helping to edit the final version of the paper. We also thank an anonymous referee for invaluable constructive criticism. The work was funded by the Trent Regional Health Authority and the Department of Health. The position of Senior Biostatistician at the Institute for Child Health Research, Perth Western Australia, is funded by the National Health and Medical Research Council of Australia.

1 Simms DG, Wynn J, Chiswick ML. Outcome for babies declined admission to a regional neonatal intensive care unit. Arch Dis Child 1982;57:334-37.

2 Alberman E, Botting B. Trends in prevalence and survival of very low birth weight infants in England and Wales 1983-1987. Arch Dis Child 1991;66:1304-8.

3 Sandhu B, Stevenson RC, Cooke RWI, Pharouh PD. Cost of neonatal intensive care for very low birth weight infants. Lancet 1986;i:600-3.

4 Ryan S, Sics A, Congdon P. Cost of neonatal care. Arch Dis Child 1988;63:303-6.

5 Fordham R, Field D, Hodges S, et al. Cost of care across a regional health authority. F Public Health Med 1992;14: 127-30.

6 The Sheldon report. Report of the expert group on the special care of babies. DHSS Report on Public Health and Medical Subjects, No 127. London: HMSO, 1974. 
7 Liaison Committee of the British Paediatric Association and the Royal College of Obstetricians and Gynaecologists. Recommendations for the improvement of infant care during the perinatal period in the UK. London: British Paediatric Association/Royal College of Obstetricians and Gynaecologists, 1977.

8 Social Services Committee. Second report from the Social Services Committee Perinatal and neonatal mortality. London: HMSO, 1980.

9 Royal College of Physicians. Medical care of the newborn in England and Wales. London: Royal College of Physicians, 1988

10 Simpson $\mathrm{H}$, Walker G. Estimating the cots required for neonatal intensive care. Arch Dis Child 1981;56:90-93.

11 Speidel BD. Skimping on care of the newborn is false economy. BMF 1986;293:575.

12 Swyer PR. The regional organisation of special care for the Neonate. Ped Clin North Am 1970;17:761-76.

13 Richardson CJ. Principles of organisation of a neonatal intensive care unit from scratch. Clinics in Perinatology 1976;3:329-35.

14 Morriss FH, Denson SE, Malloy MH, Decker M. Determination of newborn special care bed requirements by application of queuing theory to 1975-1976 morbidity experience. F Pediatrics 1978;92:668-671.
15 British Paediatric Association/British Association of Perinatal Medicine. Categories of babies requiring neonatal care. Arch Dis Child 1985;60:599-600.

16 Field D, Hodges S, Mason E, Burton P, Yates J, Wale S. The demand for neonatal intensive care. $B M \mathcal{Y} 1989 ; 299$ : 1305-8.

17 Northern Neonatal Network. Requirements for neonatal cots. Arch Dis Child 1993;68:544-9.

18 Morris D, Handyside AJ. Effect of methods of admitting emergencies on use of hospital beds. Br $\mathcal{F}$ Prev Soc Med 1971;25:1-11.

19 Office of Population Censuses and Surveys. Mortality statistics 1990. Perinatal and infant: social and biological factors. England and Wales. Series DH3 no 24. London: GovEngland and Wales. Series DH3
ernment Statistical Service, 1992.

20 Armitage P, Berry G. Statistical methods in medical research. Oxford: Blackwell Scientific Publications, 1987;60-67.

21 Pike MC, Proctor DM, Wyllie JM. Analysis of admissions to a casualty ward. Br $\mathcal{F}$ Prev Soc Med 1963;17:172-6.

22 McCullagh P, Nelder JA. Generalized linear models. Monographs on statistics and applied probability 37 . 2nd ed. Oxford: Chapman and Hall, 1989;285-96, 391-415, 471-3

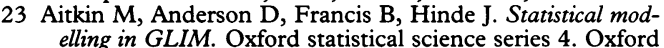
Clarendon Press, 1989. 